\title{
Multifocal Osteosarcoma
}

National Cancer Institute

\section{Source}

National Cancer Institute. Multifocal Osteosarcoma. NCI Thesaurus. Code C6470.

A primary bone osteosarcoma affecting multiple bone sites. 